\section{Editorial: A parceria entre a Revista de Sociologia e Política e o Centro Universitário Internacional Uninter}

DOI 10.1590/1678-987319276900

\author{
Lucas Massimo' (iD, Benhur Gaio" (iD, \\ Débora Veneral'II id e Siderly Almeida' ${ }^{\mathrm{IV}}$ ip \\ ${ }^{I}$ Revista de Sociologia e Política, Curitiba, PR, Brasil. \\ ${ }^{\mathrm{II}}$ Centro Universitário Internacional, UNINTER, Curitiba, PR, Brasil. \\ ${ }^{\mathrm{II}}$ Centro Universitário Internacional, UNINTER, Curitiba, PR, Brasil. \\ ${ }^{\text {IV }}$ Centro Universitário Internacional, UNINTER, Curitiba, PR, Brasil.
}

\footnotetext{
${ }^{1}$ Entre 2017 e 2019, nove estudantes formados nos cursos de Ciência Política e Relações Internacionais ingressaram no Programa de Pós-Graduação em Ciência Política (mestrado e doutorado) da UFPR. Durante esses três anos foram selecionados sessenta candidatos para as duas modalidades.
}

$\mathrm{C}$ omo já foi comunicado aos autores e pareceristas da Revista de Sociologia e Política, em 2019 nosso periódico não recebeu nenhum recurso proveniente do Governo Federal. Essa dotação vinha sendo responsável por cerca de três quartos do nosso orçamento anual e a interrupção dessa receita gerou uma série de consequências para as rotinas do periódico. Apenas na segunda quinzena de setembro desse ano conseguimos firmar uma parceria com um novo patrocinador, o Centro Universitário Internacional Uninter. Os recursos obtidos por meio desse patrocínio tornarão possível publicar todos os artigos previstos para 2019. O objetivo desse editorial é apresentar esse novo patrocinador aos leitores da Revista de Sociologia e Política.

A parceria de um periódico como o nosso e o Centro Universitário Internacional Uninter é algo bastante razoável no contexto curitibano, pois essa instituição é uma das principais empregadoras de professores nas áreas de Ciência Política e Relações Internacionais formados no Paraná. O curso de graduação em Ciência Política da Uninter foi constituído em 2000, quando a oferta de cursos específicos para essa disciplina ainda era rarefeita no Brasil. O curso de graduação em Relações Internacionais, por sua vez, foi criado um pouco mais tarde, em 2008, e desde então, e mais especificamente nos últimos três anos, os estudantes formados pelos cursos da Uninter costumam aparecer nas listas de aprovados para os programas de mestrado e doutorado na área ${ }^{1}$.

Boa parte dos professores que atuam em programas de pós-graduação nas áreas de Ciência Política e Relações Internacionais do Paraná tiveram, em algum momento de suas carreiras, algum vínculo com a Uninter, ou, em sua antiga denominação, com a Facinter (Faculdade Internacional de Curitiba). A manutenção desse pessoal ao longo dos anos possibilitou o acúmulo de experiência, que se exprime nos resultados acadêmicos obtidos pelos cursos de Ciência Política e Relações Internacionais da instituição. A partir de agosto de 2014, os dois cursos deram início a oferta na modalidade EAD e no primeiro semestre de 2019 a Instituição recebeu pela primeira vez as comissões designadas pelo MEC para realizar a visita in loco para reconhecimento desses dois cursos.

O resultado não poderia ser melhor. O bacharelado em Ciência Política EAD e o bacharelado em Relações Internacionais EAD foram reconhecidos com a nota 5, que exprime o conceito mais elevado para cursos de graduação. Para efeito de comparação, dos 26 cursos de graduação em Ciência Política 
2 Aqui vale uma observação de ordem procedimental. $\mathrm{O}$ bacharelado em Ciência Política na modalidade EAD recebeu a comissão responsável pelo reconhecimento do curso em março de 2019 e na segunda quinzena de outubro, quando esse editorial foi redigido, a nota 5 ainda não tinha sido publicada na plataforma e-MEC. É possível que isso se estenda a outros cursos.

\footnotetext{
3 Aludimos à primeira parte da primeira aula registrada em meios eletrônicos acerca de como se emitem pareceres científicos. A versão integral dessa exposição, que aconteceu em fevereiro de 2015, está disponível em https://youtu.be/GFmhRNJzyx
}

relacionados na plataforma e-MEC (http://emec.mec.gov.br/emec/), apenas três possuem esse resultado no indicador conceito de $\mathrm{curso}^{2}$, os cursos da Universidade Federal de Pernambuco (com duas notas cinco consecutivas, uma em 2012 e outra em 2019); da Universidade Federal do Pampa (avaliado com a nota $5 \mathrm{em}$ 2015); e o curso de Ciência Política da Uninter na modalidade presencial (avaliado com a nota 5 em 2012, 2015 e 2018), somando-se a nota 5 recebida no Curso de Ciência Política EAD (2019).

Na área de Relações Internacionais, a oferta de cursos de graduação já está consolidada e atualmente existem 202 cursos cadastrados na plataforma eMEC. Desse total, 40 possuem o conceito 5.

A obtenção desse resultado na primeira visita de reconhecimento dos cursos EAD foi possível graças à manutenção, por muitos anos, de professores experientes e dedicados, cujo trabalho se cristalizou em uma matriz curricular coerente e consistente, sem a qual não seria possível atender aos rigorosos critérios previstos no instrumento de avaliação aos quais os cursos foram submetidos.

Contudo, não é apenas a afinidade entre os cursos da Uninter e os temas preferidos pela Revista de Sociologia e Política que justifica essa parceria, tendo em vista a instituição contar com dois Programas de Pós-Graduação stricto sensu, o Mestrado Profissional em Educação e Novas Tecnologias e o Mestrado Acadêmico em Direito. De acordo com as informações recebidas da Coordenação de Pesquisa e Publicações Acadêmicas, departamento vinculado à Pró-Reitoria de Pós-Graduação, Pesquisa e Extensão da Uninter, estão em andamento nos dois programas de mestrado trinta e três projetos de pesquisa. $\mathrm{O}$ Mestrado em Educação possui quatro grupos, que são responsáveis por onze linhas de pesquisa, e o Mestrado em Direito é composto por quatro grupos de pesquisa, com quatro linhas de investigação.

Os títulos dos grupos e linhas, com seus respectivos projetos, estão relacionados no Quadro 1. Como se pode constatar nos títulos dos projetos de pesquisa, há uma clara orientação para a pesquisa aplicada, ou seja, os projetos conduzidos nos dois programas de pós-graduação têm em seu horizonte a interação com os sujeitos de pesquisa e a transformação, em médio prazo, dos contextos em que são conduzidas as atividades de investigação.

Como é de conhecimento público, o sistema de comunicação científica é um dispositivo incontornável para a produção científica, uma vez que é por meio das publicações periódicas que os resultados das investigações são disponibilizados para a comunidade. Como já dissemos alhures ${ }^{3}$, o sistema de publicações seriadas exerce três funções elementares: as revistas científicas divulgam os resultados obtidos nas investigações, elas qualificam a produção acadêmica, e oferecem para os organismos de fomento indicadores objetivos para mensurar o desempenho dos cientistas na atividade de pesquisa. Ao divulgar os resultados obtidos em pesquisas empiricamente orientadas, a comunidade científica pode se comunicar com outros públicos, pois com a publicação de artigos em modelo aberto e irrestrito - tal como adotado pelos periódicos indexados na coleção SciELO Brasil - mesmo leitores que não estão diretamente vinculados com as rotinas da pesquisa científica podem ter acesso aos resultados dessas investigações.

A qualificação da produção acadêmica ocorre por meio da chancela conferida aos manuscritos pelo sistema de avaliação por pares, que avaliam os textos elaborados pelos pesquisadores com base em diversos critérios editoriais. Sob o ponto de vista dos organismos de fomento, o sistema de publicações científicas hierarquiza os periódicos e escalona, através dos extratos mais qualificados, as 
Quadro 1 - Relação de grupos, linhas e projetos de pesquisa com pesquisadores ativos durante o ano de 2019

\begin{tabular}{|c|c|c|c|}
\hline Vínculo Institucional & Grupo de pesquisa & Linha de pesquisa & Projeto de pesquisa \\
\hline \multirow[t]{18}{*}{$\begin{array}{l}\text { MESTRADO EM } \\
\text { EDUCAÇÃO }\end{array}$} & $\begin{array}{l}\text { I. Ciência, Tecnologia } \mathrm{E} \\
\text { Interculturalidade } \mathrm{Na}\end{array}$ & 1. Ciência, Tecnologia e Interculturalidade na Educação & 1a. Ciência, tecnologia e interculturalidade na educação \\
\hline & Educação & & 1b. Educação e direitos humanos \\
\hline & & $\begin{array}{l}\text { 2. Currículo e Formação de Professores para } \\
\text { Ciência, Tecnologia e Interculturalidade }\end{array}$ & $\begin{array}{l}\text { 2a. Currículo e formação de professores para } \\
\text { ciência, tecnologia e interculturalidade }\end{array}$ \\
\hline & & $\begin{array}{l}\text { 3. Fundamentos Teóricos e Metodológicos da Educação } \\
\text { Ambiental }\end{array}$ & $\begin{array}{l}\text { 3a. Práticas em educação ambiental: planejamento, execução e } \\
\text { avaliação }\end{array}$ \\
\hline & & & $\begin{array}{l}\text { 3b. O professor/educador na Cidade Educadora: } \\
\text { políticas, práticas e representações sociais }\end{array}$ \\
\hline & $\begin{array}{l}\text { II. Novas Tecnologias De } \\
\text { Ensino e Aprendizagem }\end{array}$ & 4. Simulação Computacional E Robótica Educacional & 4a. Simuladores computacionais e robótica educacional \\
\hline & & & 4b. Aplicação de algoritmos para ciência de dados \\
\hline & & & 4c. Desenvolvimento de software para scanner 3D \\
\hline & & 5. Formação Docente em Contexto na Educação & $\begin{array}{l}\text { 5a. Formação do docente no contexto da sua prática: integração } \\
\text { significativa das tecnologias na educação superior }\end{array}$ \\
\hline & & & $\begin{array}{l}\text { 5b. Formação do docente no contexto da sua prática: integração } \\
\text { significativa das tecnologias na educação básica }\end{array}$ \\
\hline & & $\begin{array}{l}\text { 6. Meta-Avaliação De Processo Normativo E Instrumental De } \\
\text { Avaliação }\end{array}$ & $\begin{array}{l}\text { 6a. Meta-avaliação de processo normativo e instrumental de } \\
\text { avaliação }\end{array}$ \\
\hline & & $\begin{array}{l}\text { 7. Educação Híbrida: Metodologias e Objetivos de } \\
\text { Aprendizagem Digitais em Ambientes de Mobilidade }\end{array}$ & $\begin{array}{l}\text { 7a. Metodologias e objetos de aprendizagem digitais em } \\
\text { ambientes de mobilidade tecnológica }\end{array}$ \\
\hline & III. Educação a Distância & 8. Tecnologia Educacional & $\begin{array}{l}\text { 8a. Educação a distância no ensino superior no brasil: } \\
\text { metodologias e tecnologias }\end{array}$ \\
\hline & & 9. Formação de Professores & $\begin{array}{l}\text { 9a. Docência e aprendizagem para a educação híbrida e a } \\
\text { distância }\end{array}$ \\
\hline & $\begin{array}{l}\text { IV. Educação, Tecnologia e } \\
\text { Sociedade }\end{array}$ & 10. Métodos e Metodologias Mediadas por Tecnologias & $\begin{array}{l}\text { 10a. Formação de professores e inovações metodológicas e } \\
\text { tecnológicas no cotidiano escolar }\end{array}$ \\
\hline & & $\begin{array}{l}\text { 10b. Formação integral, mediação e tecnologia no cotidiano } \\
\text { escolar }\end{array}$ & \\
\hline & & $\begin{array}{l}\text { 10c. Processos de formação de professores: relações com o } \\
\text { desenvolvimento profissional docente }\end{array}$ & \\
\hline & & 11. Educomunicação & 11a. Cinema e outras linguagens audiovisuais na educação \\
\hline
\end{tabular}




\begin{tabular}{lll}
\hline Vínculo Institucional & Grupo de pesquisa & Linha de pesquisa \\
\hline MESTRADO EM & I. Processo e Efetividade da & 1. Jurisdição e Processo na Contemporaneidade \\
DIREITO & Tutela Jurisdicional
\end{tabular}

DIREITO

II. Direito, História e Poder 2. Teoria e História da Jurisdição Judiciário

III. Historicidade e História 3. Teoria e História da Jurisdição do Pensamento

Jurídico-Político

IV. Teoria Contemporânea 4. Jurisdição e Processo na Contemporaneidade da Jurisdição e Direito

Público

\section{Projeto de pesquisa} diálogos

1b. Análise econômica da atividade jurisdicional do STF: uma avaliação empírico-jurimétrica

1c. Recortes da relação entre judiciário, executivo e legislativo na perspectiva penal: a conformação do poder punitivo diante da complexa interação entre poderes

1d. Jurisdição, processo e direitos fundamentais dos consumidores: avanços, retrocessos, perspectivas

1e. Jurisdição e processo: concepções contemporâneas da justiça de transição

2a. Economia política e direito penal: as razões econômicas do crime

2b. Concepções filosóficas de poder

2c. Legislação e jurisdição: política e direito em lógica e argumentação

2d. A economia da política criminal: relações entre a política de drogas e dependência econômica na América Latina

2e. Consequências psicológicas do encarceramento:

reconhecimento e ressocialização

3a. Justiça e poder político: o lugar do judiciário no espaço público e a apropriação do direito como recurso de luta política

3b. História da cultura jurídica brasileira

4a. Judicialização da política e controle judicial de políticas públicas

4b. Tripartição dos poderes e nova ordem mundial jurisdições, administrações e parlamentos internacionais

4c. A administração pública e seu controle interno (mediante autotutela), externo (pelos tribunais de contas) e pelo próprio poder judiciário - possibilidades e limites; excessos e desvios

Fonte: Elaboração própria, com base nos dados fornecidos pela Coordenação de Pesquisa e Publicações Acadêmicas. 
linhas de pesquisa e as áreas do conhecimento que devem receber os recursos destinados à produção científica.

Dizemos que essas três funções elementares são exercidas por um sistema de publicações (e não apenas por um periódico em particular), tendo em vista que uma comunidade científica consolidada pressupõe uma "ecologia de periódicos", vale dizer, a pluralidade de orientações teóricas e metodológicas presentes em diversas áreas do conhecimento deve estar expressa na diversidade de periódicos aos quais os pesquisadores submetem seus manuscritos.

Todavia, a reprodução de uma comunidade científica pressupõe a existência de uma formação sólida em nível de graduação. A renovação dos estudantes engajados nas atividades de pesquisa está diretamente relacionada ao ensino superior qualificado de amplitude nacional, que não se restrinja aos grandes centros urbanos. Essa preocupação converge com os princípios institucionais que orientam o planejamento estratégico do Centro Universitário Internacional Uninter, dentre eles, a universalização do acesso às vagas para o ensino superior no Brasil. Esse é um assunto importante para essa instituição e gostaríamos de levar ao conhecimento dos leitores da Revista de Sociologia e Política mais alguns detalhes a esse respeito.

O Centro Universitário Internacional Uninter conta hoje com mais de 800 Polos de Apoio Presencial (PAPs) credenciados pelo MEC em todo o Brasil e mais cinco Polos no exterior, nos quais atende ao todo, aproximadamente, mais de 230 mil alunos. Para atender esse público, conta com um quadro docente de 405 professores, composto de mais de 290 mestres e doutores, características que o classificam como a segunda maior Instituição de Ensino Superior em EAD do país. Um dos aspectos que singulariza a missão da instituição é a distribuição de livros impressos para estudantes de graduação na modalidade a distância. Entre janeiro e setembro de 2019, o Centro Universitário Internacional Uninter distribuiu por todo o território nacional 418.361 kits com livros para estudantes matriculados em 46 cursos de graduação. Os cursos com a maior quantidade de kits enviados são Pedagogia (82.250), Administração (36.709) e Ciências Contábeis (24.219). No outro extremo, os cursos com as menores quantidades de kits enviados são Gestão de Organizações do Terceiro Setor (125 kits), Gestão de Trânsito e Mobilidade Urbana (311 kits) e Física (339 kits).

O sistema adotado pelos cursos de graduação oferta as disciplinas em um calendário quadrimestral, com três módulos por ano. Cada módulo é formado por duas fases, e cada fase possui duas disciplinas. Assim, via de regra, cada kit é composto por quatro livros, um para cada disciplina do módulo. Há alguns cursos que podem enviar mais ou menos exemplares impressos, mas de modo geral, e de acordo com o relato dos responsáveis pelo departamento de Suprimentos, Compras e Logística, é possível afirmar que apenas nos primeiros nove meses desse ano, foram distribuídos cerca de um milhão e meio de exemplares impressos em todos os estados brasileiros.

Os kits são enviados para os Polos de Apoio Presencial e os estudantes precisam se deslocar até seus Polos para retirar seus kits. É importante frisar que esses livros não foram "comercializados", pois nos cursos em que há distribuição de exemplares impressos, o envio de livros não gera nenhuma espécie de ônus adicional aos estudantes, ou seja, o estudante recebe os livros quer queira, quer não. A Tabela 1 apresenta a quantidade de kits distribuídos para cada módulo.

Para se ter uma ideia da cobertura nacional dos alunos atendidos por esses kits, classificamos as cidades em que estão situados os polos como capital ou interior do estado. Dos 418 mil kits, 82,1\% foram enviados para polos situados em 
Tabela 1 - Quantidade de kits distribuídos por módulo (janeiro a setembro de 2019)

\begin{tabular}{lcc}
\hline Módulo (período das disciplinas) & Frequência & Percentual \\
\hline Módulo A (março-maio) & 181.888 & 43,5 \\
Módulo B (junho-agosto) & 117.694 & 28,1 \\
Módulo C (setembro-dezembro) & 118.779 & 28,4 \\
Total & 418.361 & 100 \\
\hline
\end{tabular}

Fonte: elaboração própria, com base nos dados fornecidos pelo departamento de Suprimentos, Compras e Logística.

cidades do interior dos Estados (343.638 kits). Os outros 74.723 kits foram enviados para polos situados nas capitais dos 27 Estados da Federação Brasileira.

Na estrutura acadêmica do Centro Universitário Internacional Uninter, as atividades nos cursos de graduação são organizadas em "Escolas Superiores", e a Tabela 2 apresenta o resultado da variável dicotômica (capital versus interior) por escola, para que se possa ter uma noção da cobertura nacional de modo mais inteligível.

Por meio da Tabela 2, pode-se constatar que a Escola Superior de Gestão Pública, Política, Jurídica e Segurança se diferencia das demais sob o ponto de vista da capilaridade na distribuição dos kits. Ocorre que o público da maioria dos cursos ofertados por esta escola, em razão da atuação na área pública, se concentra nas capitais dos estados. Ainda assim, mesmo nessa escola, foram distribuídos mais de 35 mil kits para Polos situados nos munícipios do interior dos Estados, totalizando cerca de cento e quarenta mil exemplares impressos distribuídos nos primeiros nove meses deste 2019.

É importante destacar que, via de regra, esses exemplares são utilizados como base bibliográfica do conteúdo que será discutido nas videoaulas. O

Tabela 2 - Quantidade de Kits distribuídos em Polos situados na capital do Estado ou em municípios do interior, por escola (janeiro a setembro de 2019)

\begin{tabular}{lccc}
\hline \multirow{2}{*}{ Escolas } & \multicolumn{2}{c}{ Tipo de Município } & \multirow{2}{*}{ Subtotal } \\
\cline { 2 - 3 } & Capital de estado & $\begin{array}{c}\text { Município do } \\
\text { interior }\end{array}$ & \\
\hline Escola Politécnica & 1.805 & 14.788 & \multirow{2}{*}{16.593} \\
& $10,9 \%$ & $89,1 \%$ & \\
Escola Superior de Educação & 29.840 & 161.739 & \multirow{2}{*}{191.579} \\
& $15,6 \%$ & $84,4 \%$ & \\
Escola Superior de Gestão, Comuni- & 24.659 & 108.506 & 133.165 \\
cação e Negócios & $18,5 \%$ & $81,5 \%$ & \\
Escola Superior de Saúde, Biociên- & 4.011 & 21.316 & 25.327 \\
cia, Meio Ambiente e Humanidades & $15,8 \%$ & $84,2 \%$ & \multirow{2}{*}{51.697} \\
Escola Superior de Gestão Públi- & 14.408 & 37.289 & \\
ca, Política, Jurídica e Segurança & $27,9 \%$ & $72,1 \%$ & \multirow{2}{*}{418.361} \\
Totais & 74.723 & 343.638 & \\
\hline
\end{tabular}

Fonte: elaboração própria, com base nos dados fornecidos pelo departamento de Suprimentos, Compras e Logística. 
mesmo conteúdo é objeto da avaliação dos alunos por parte da Instituição, o que por si só, representa um incentivo importante para a leitura. Ademais, a produção dos exemplares é realizada por um selo editorial próprio, que viabiliza a realização de um rigoroso processo de arbitragem por pareceres anônimos, emitidos em versões preliminares dos manuscritos que dão origem aos livros base das disciplinas. Essa informação é útil para destacar a centralidade atribuída aos livros no modelo de ensino adotado pelo Centro Universitário Internacional Uninter.

Finalmente, para dar uma ideia da capilaridade na distribuição destes livros, apresentaremos os percentuais dessa mesma variável por estado (como se vê na Tabela 3).

A Tabela 3 revela que o Pará é o estado em que o maior percentual de kits destinaram-se a municípios do interior. Esses dados são úteis para se ter um panorama da capilaridade da cobertura em nível nacional, mas eles não nos

Tabela 3 - Percentual de Kits distribuídos em Polos situados na capital do Estado ou em municípios do interior, por estado (janeiro a setembro de 2019)

\begin{tabular}{lcc}
\hline Estado & \multicolumn{2}{c}{ Tipo de município } \\
\cline { 2 - 3 } & Capital de estado & Município do interior \\
\hline Pará & $7,0 \%$ & $93,0 \%$ \\
São Paulo & $7,6 \%$ & $92,4 \%$ \\
Santa Catarina & $8,4 \%$ & $91,6 \%$ \\
Rio Grande do Sul & $9,1 \%$ & $90,9 \%$ \\
Bahia & $9,4 \%$ & $90,6 \%$ \\
Espírito Santo & $10,6 \%$ & $89,4 \%$ \\
Mato Grosso & $11,4 \%$ & $88,6 \%$ \\
Minas Gerais & $12,3 \%$ & $87,7 \%$ \\
Tocantins & $22,3 \%$ & $77,7 \%$ \\
Maranhão & $22,8 \%$ & $77,2 \%$ \\
Paraná & $23,5 \%$ & $76,5 \%$ \\
Rio de Janeiro & $29,9 \%$ & $70,1 \%$ \\
Alagoas & $32,5 \%$ & $67,5 \%$ \\
Pernambuco & $32,6 \%$ & $67,4 \%$ \\
Goiás & $34,3 \%$ & $65,7 \%$ \\
Acre & $36,5 \%$ & $63,5 \%$ \\
Distrito Federal & $43,2 \%$ & $56,8 \%$ \\
Paraíba & $44,5 \%$ & $55,5 \%$ \\
Piauí & $45,8 \%$ & $54,2 \%$ \\
Amapá & $53,0 \%$ & $47,0 \%$ \\
Mato Grosso do Sul & $43,5 \%$ \\
Ceará & $56,5 \%$ & $40,4 \%$ \\
Rondônia & $59,6 \%$ & $32,3 \%$ \\
Sergipe & $67,7 \%$ & $23,0 \%$ \\
Amazonas & $77,0 \%$ & $1 \%$ \\
Roraima & & \\
\hline & $100 \%$ & \\
\hline
\end{tabular}

Fonte: elaboração própria, com base nos dados fornecidos pelo departamento de Suprimentos, Compras e Logística. 
4 Todos os dados que se referem ao IBGE foram retirados da página do próprio Instituto, disponível em https://cidades.ibge.gov.br/bra sil/pa/afua/panorama Acesso em 17 out. 2019 ajudam a compreender exatamente que impacto a oferta de cursos de graduação na modalidade EAD pode ter em pequenos municípios do interior. Para essa finalidade, examinaremos a experiência com o município de Afuá, uma das doze cidades paraenses que fazem parte da Ilha de Marajó, e que tem uma população estimada de 39.218 habitantes (IBGE, 2019) $)^{4}$ das quais 2.506 pessoas possuem alguma ocupação no que se refere a trabalho/emprego, o que representa 6,6\% da população total. Quanto à educação, o município de Afuá tem 1.057 alunos matriculados no ensino médio e apenas 26 docentes com formação para atuar neste nível de ensino.

Isto é reflexo da falta de instituições de ensino superior que ofertem vagas na cidade, pois, segundo o Plano Municipal de Educação de Afuá, "No município de Afuá, esse acesso, principalmente pelos jovens, tem sido carente, pois observa-se que atualmente não se tem oferecido a oportunidade de ingresso e permanência ao ensino superior no próprio município." (AFUÁ, 2015, p. 85)

O compromisso de uma instituição de ensino que se propõe a democratizar o acesso à educação deve ir além da oferta de um processo de ensino e de aprendizagem livresco que desconsidera a vivência, a experiência e a rotina daqueles que se inscrevem em seus cursos. É preciso favorecer a autonomia do aluno no sentido de possibilitar a liberdade para escolher os caminhos que pretende seguir e, ainda, contribuir para a construção de tal caminho, assim como, para a construção do próprio ser.

Considerando-se, neste contexto, que a prática educativa precisa ser dialógica, reflexiva, e, para usar um termo freireano, libertária (FREIRE, 1996) ${ }^{6}$ faz-se necessário refletir que o processo de ensino e de aprendizagem é um ato político, pois oportuniza uma transformação pessoal e social.

Voltando a Afuá, entre as estratégias delineadas pela prefeitura para dar conta da demanda por ensino superior, propõe-se o seguinte objetivo: "mapear a demanda e fomentar através de parcerias a oferta de formação de pessoal de nível superior, destacadamente a que se refere à formação nas áreas de carência local, considerando a melhoria da qualidade da educação básica." (AFUA, 2015, p. 86)

Nesse sentido, o Centro Universitário Internacional Uninter, buscando atender democraticamente esta população, abriu no início de 2018, um polo em Afuá ofertando cursos de formação de professores na modalidade a distância. Isso possibilitou que os estudantes que antes precisavam viajar dez horas para chegar a cidade de Macapá e frequentar uma faculdade, pudessem ter acesso ao estudo, locomovendo-se por meio de bicicleta, uma vez que na cidade não há automóveis?

$\mathrm{O}$ amadurecimento e crescimento de uma população não se faz da noite para o dia, é preciso construir-se diariamente. Cabe a educação, para além de conduzir este processo de maturação, estimular para que o estudante opte por esta libertação, pela maturidade, e pela incansável busca por emancipação, autonomia e consequente amadurecimento individual e social. E, neste caso, a educação é o melhor investimento, ainda que em lugares precários.

Tendo essa caracterização em mente, podemos retomar ao ponto central que nos levou à redação desse editorial. Não fosse o patrocínio dessa instituição, não haveria recursos para garantir a publicação dos artigos aprovados na Revista de Sociologia e Política em 2019. Mas, afinal, por que uma instituição de ensino privada como o Centro Universitário Internacional Uninter manifestaria interesse na manutenção de um periódico como a Revista de Sociologia e Política?

Por duas razões. A primeira é de ordem estritamente acadêmica. O sistema de publicações científicas permite aos coordenadores de curso manter a biblio- 
8 Um hábito ainda pouco disseminado entre professores e estudantes de graduação, que se exprime na ausência desse gênero de texto científico em planos de ensino, e ajuda a compreender a baixa quantidade de citações recebidas pelos periódicos brasileiros. grafia dos Projetos Pedagógicos de Curso (PPCs) devidamente atualizada. O investimento na comunicação científica é necessário para manter a comunidade científica atuante, produzindo conhecimentos novos, de maneira que os conteúdos das disciplinas não se restrinjam aos livros bases delas. Além disso, durante o transcorrer dos cursos, os estudantes podem enriquecer sua formação, se familiarizar já em nível de graduação, com a leitura de $\operatorname{artigos~científicos~}^{8}$. O dinamismo das plataformas de ensino e aprendizagem possibilita a alimentação e retroalimentação de conteúdo, e as revistas científicas, como vimos acima, cumprem esse papel.

A segunda razão que justifica um apoio dessa natureza é de ordem estratégica. Por meio dessa parceria, o Centro Universitário Internacional Uninter almeja se apresentar para a comunidade acadêmica de Ciência Política e Relações Internacionais, e visa dar conhecimento à comunidade acadêmica do trabalho realizado na área educacional em todo o Brasil. A Uninter pretende continuar a auxiliar na disseminação de conhecimentos agora, também, por intermédio da Revista de Sociologia e Política. O Centro Universitário Internacional Uninter apoia a produção de conhecimento empiricamente orientado uma vez que direciona recursos para a comunicação científica, neste caso, com o financiamento de um periódico de referência para as áreas de Ciência Política e Relações Internacionais.

Ainda não sabemos por quanto tempo esse patrocínio se manterá. Esperamos criar condições para que esse apoio ofereça aos editores da Revista de Sociologia e Política uma base de financiamento sólido e regular. A cristalização de um novo modelo de financiamento à comunicação científica requer tempo. Esperamos também que nos próximos anos possamos continuar apresentando aos leitores da Revista de Sociologia e Política novidades a esse respeito.

Lucas Massimo, Benhur Gaio, Débora Veneral e Siderly Almeida (com a colaboração de Caroline Cordeiro e Tania Frugiuele Soares Agostinho)

Lucas Massimo (LUCAS.SO@uninter.com) é coordenador de cursos de graduação no Centro Universitário Internacional Uninter e editor da Revista de Sociologia e Política.

Benhur Gaio (BENHUR.G@ uninter.com) é reitor do Centro Universitário Internacional Uninter.

Débora Veneral (DEBORA.V@ uninter.com) é diretora da Escola Superior de Gestão Pública, Política, Jurídica e Segurança do Centro Universitário Internacional Uninter.

Siderly Almeida (SIDERLY.A@ uninter.com) é coordenadora do Mestrado Profissional em Educação e Novas Tecnologias do Centro Universitário Internacional Uninter.

This is an Open Access article distributed under the terms of the Creative Commons Attribution Non-Commercial License which permits unrestricted non-commercial use, distribution, and reproduction in any medium provided the original work is properly cited. 